\title{
The \\ Relationship of Alcohol Safety Laws to Drinking Drivers in Fatal Crashes
}

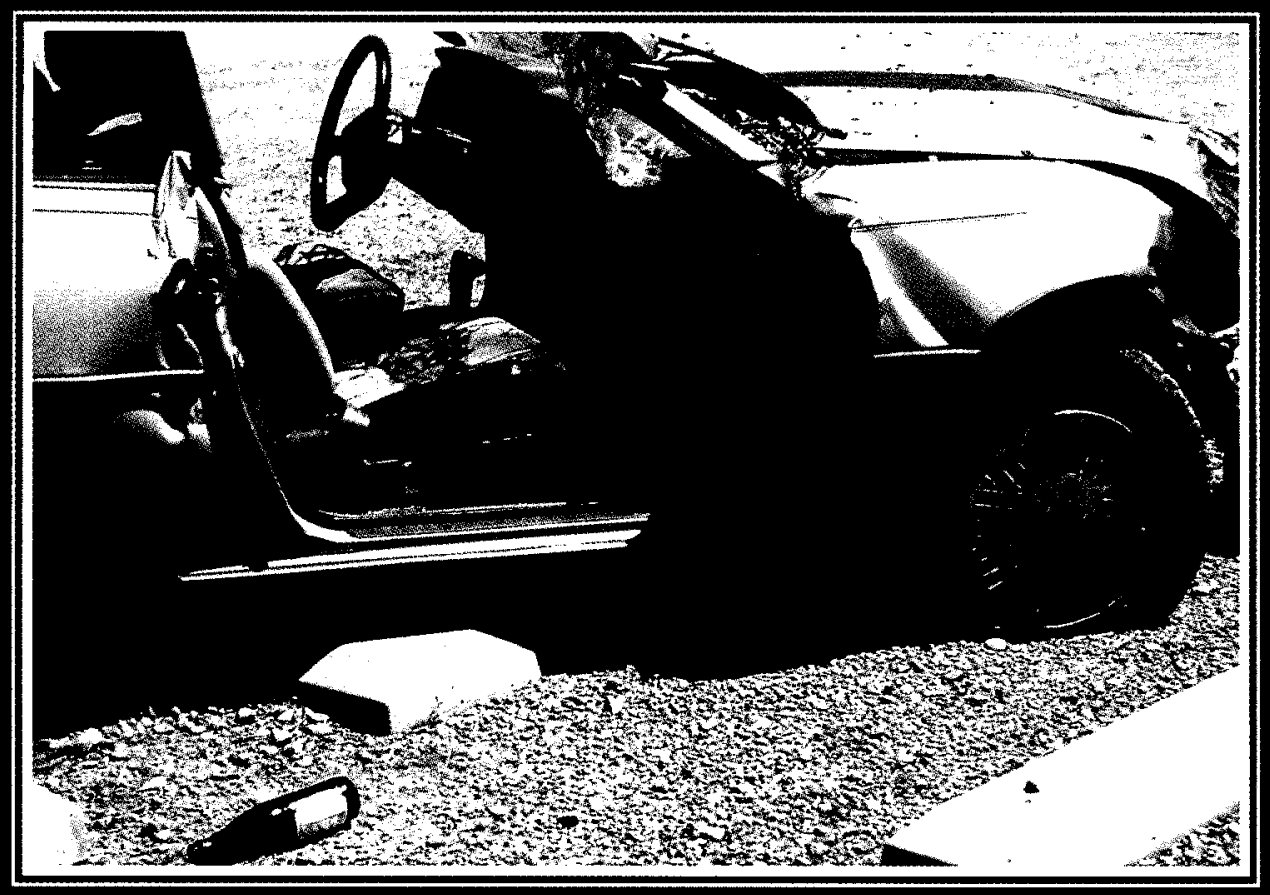

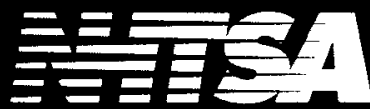 \\ People Saving People \\ www.nhtsa.dot.gov}




\title{
The Relationship of Alcohol Safety Laws to Drinking Drivers in Fatal Crashes
}

\author{
prepared for: \\ Department of Transportation \\ National Highway Traffic Safety Administration \\ $4007^{\text {th }}$ Street, SW \\ Washington, DC 20590 \\ prepared by: \\ Robert B. Voas and A. Scott Tippetts \\ Pacific Institute for Research and Evaluation \\ 7315 Wisconsin Avenue \\ Suite 1300 West \\ Bethesda, Maryland 20814
}

April 15, 1999 


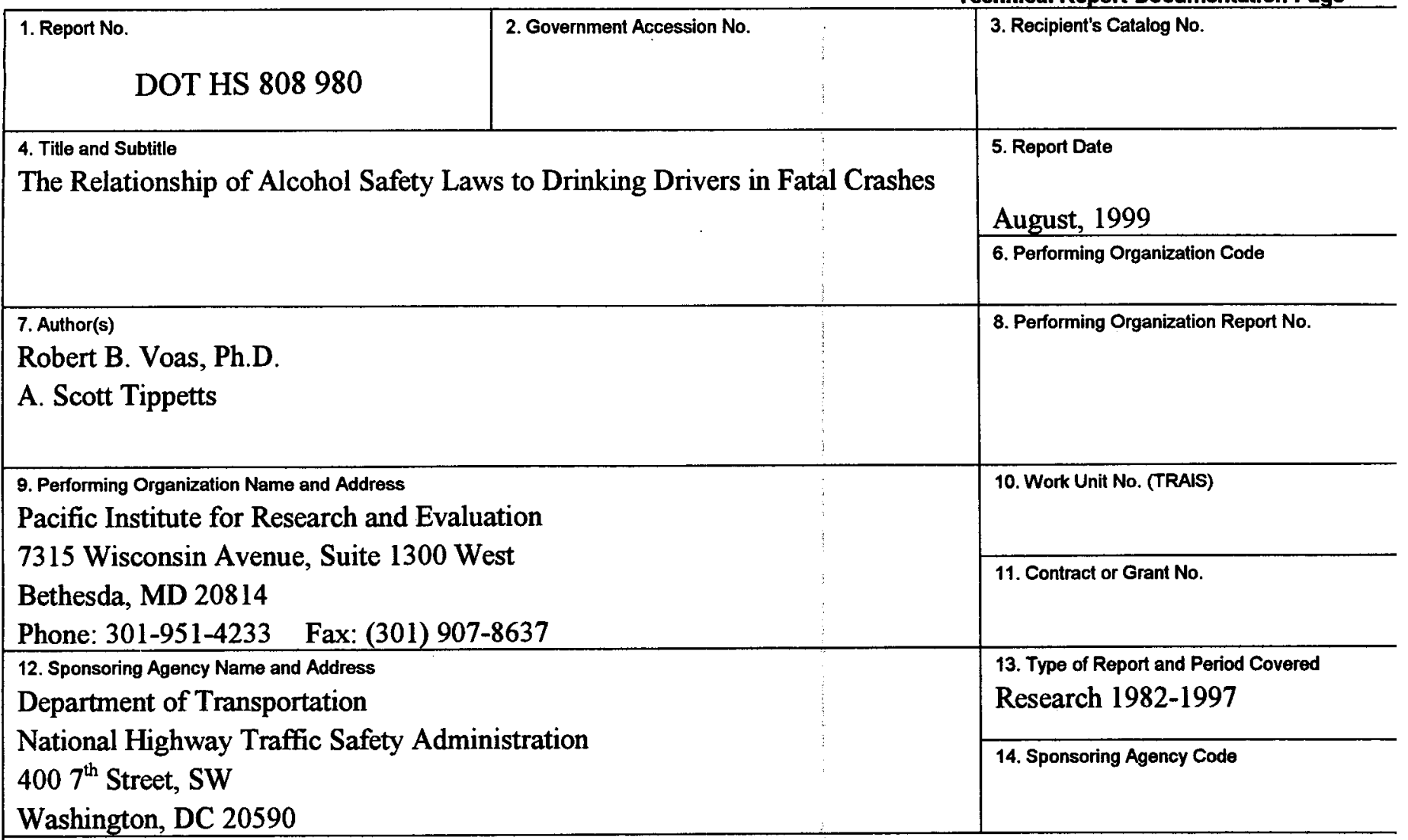

15. Supplementary Notes

16. Abstract

This paper presents an analysis of the relationships between the passage of key alcohol safety laws and the number of drinking drivers in fatal crashes. The study evaluated three major alcohol safety laws (administrative license revocation laws, .10 illegal per se, and .08 illegal per se laws) on the proportion of drinking drivers in fatal crashes. Drivers age 21 and older in fatal crashes at two BAC levels- 01 to .09 , and .10 or greater-were considered separately. Drivers under age 21 were not included because they are affected by the Minimum Legal Drinking Age law. This study used data on drinking drivers in fatal crashes from the Fatality Analysis Reporting System (FARS) covering 16 years from 1982 though 1997 for all 50 states and the District of Columbia. Also included in the study were such variables as per-capita alcohol consumption and annual vehicle miles traveled, which could impact the number of alcohol-related crashes. The results indicate that each of the three laws had a significant relationship to the downward trend in alcohol-related fatal crashes in the United States over that period. The paper points out that this long-term trend is not the product of a single law, but the result of the growing impact of several laws over time plus the affect of some factors not included in the model tested, such as the increasing use of sobriety checkpoints and the media's attention to the drinking-and-driving problem.

17. Key Words

drinking drivers, ALR laws, per se laws, zero tolerance laws, MLDA laws
18. Distribution Statement
This document can be found on NHTSA's homepage:
http://www.nhtsa. dot.gov
It is also available from the National Technical
Information Service, Springfield, VA (703-605-6000)

20. Security Classif. (of this page)

Unclassified

\begin{tabular}{|l|l}
\hline 21 No. of Pages & 22. Price \\
24 for report & \\
5 for appendices & \\
\hline
\end{tabular}




\section{Alcohol Safety Laws and Fatal Crashes}

\section{EXECUTIVE SUMMARY}

Since 1982 when the Fatality Analysis Reporting System (FARS) began to impute blood alcohol concentration (BAC) data for all crash-involved drivers, the U.S. population covered by illegal per se laws with at least a .10 BAC has increased from $32 \%$ to $98 \%$; the population covered by Administrative License Revocation (ALR) laws has increased from 6\% to 78\%; and the population covered by the lower .08 illegal per se $(.08 \mathrm{BAC})$ laws has increased from $0 \%$ to $28 \%$. During the same period (1982 to 1997), the proportion of all fatalities that are alcoholrelated dropped from $57 \%$ to $39 \%$. This drop was undoubtedly due to a variety of factors including the many actions undertaken in the various states to combat alcohol-impaired driving. This study looked at the extent to which the reduction in alcohol-related fatalities can be attributed to the three laws mentioned above. After controlling for various extraneous factors, the analysis found that all three laws were associated with significant reductions in fatal crashes involving drinking drivers.

Other studies have found effectiveness of each of the three laws included in this study. However, this was the most comprehensive study which has been conducted to look at these three important laws. FARS data from all 50 states and the District of Columbia, for the 16 years from 1982 through 1997, were included in the study. Using weighted least squares (WLS) regression models, the study tested for reductions in the involvement of drivers with low BACs and drivers with high BACs in fatal crashes. To control for extraneous factors that could affect all fatal crashes, the ratio of alcohol-positive to alcohol-negative drivers involved in fatal crashes was used as the dependent variable. The study also controlled for the effects of other potentially confounding trends in demographic, economic, alcohol consumption, and seasonal factors, as well as for an increase in the number of states with safety belt use laws.

In addition, a "time trend" variable, representing each year from 1982 through 1997, was entered into the analysis to control for unknown or unmeasurable time-related factors. Again, separate analyses were performed for drivers at lower BAC levels (.01-.09) and those at high BAC levels $(\geq .10)$. The results included in the following table show that the ALR law and the two illegal per se $\mathrm{BAC}$ laws $(.10 \mathrm{BAC}$ and $.08 \mathrm{BAC})$ all showed significant negative relationships with alcohol involvement among drivers in fatal crashes. With regard to $.08 \mathrm{BAC}$ laws, the results suggested that these laws were associated with 8 percent reductions in the involvement of both high BAC and lower BAC drivers in fatal crashes. Combining the results for the high and low BAC drivers, it is estimated that 275 lives were saved by .08 BAC laws in 1997. If all 50 states (rather than 15 states at the time of this study) had such laws in place in 1997, an additional 590 lives could have been saved. 


\section{Alcohol Safety Laws and Fatal Crashes}

EFFECT SIZES FOR ALCOHOL SAFETY FOR TWO GROUPS OF DRIVERS IN FATAL CRASHES

\begin{tabular}{l|cc}
\hline Alcohol Safety Laws & \multicolumn{2}{|l}{ Adult drivers in fatal crashes } \\
\hline & BAC .01-.09 & BAC .10+ \\
Illegal per se laws (.10) & $-13.17 \%$ & $-8.69 \%$ \\
Per se .08 law & $-7.89 \% *$ & $-8.00 \%$ \\
Admin. license revocation law & $-18.96 \%$ & $-12.81 \%$ \\
\hline
\end{tabular}

* Significant at $p=.05 ;$ all other significant at $p<.001$

Because the passage of alcohol safety laws by the states took place over time and is highly correlated with time, it was felt that the introduction of the "time trend" factor absorbed some additional impact properly attributable to the three laws in question and, thus, this analysis produced conservative estimates of the potential impact of these three laws.

Finally, the attribution of savings to any single law should be made with caution since each new law builds to some extent on existing legislation and on other ongoing trends and activities. The synergistic interaction among laws is perhaps most evident in the relationship between illegal per se laws (.10 BAC and .08 BAC) and ALR laws. 


\section{Alcohol Safety Laws and Fatal Crashes \\ TABLE OF CONTENTS}

Form DOT F 1700.7-Technical Report Documentation Page..................................... ii

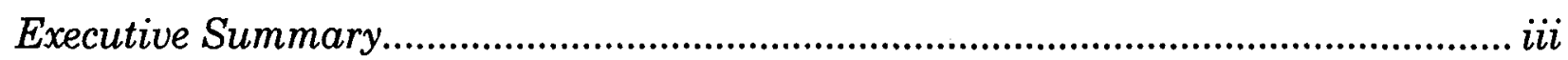

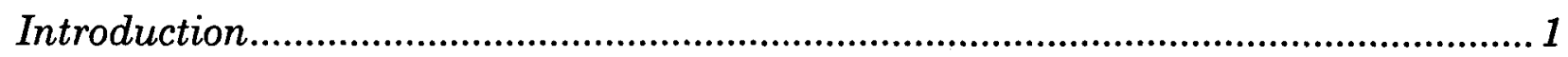

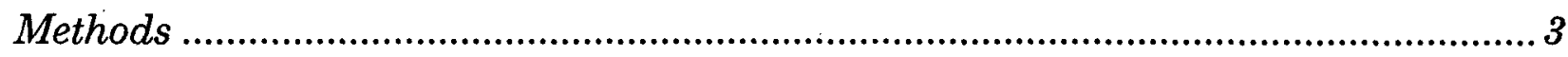

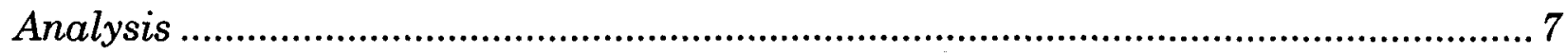

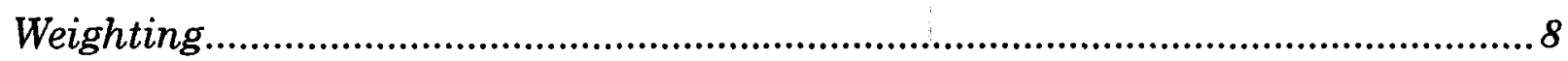

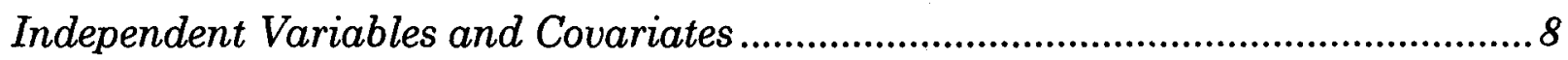

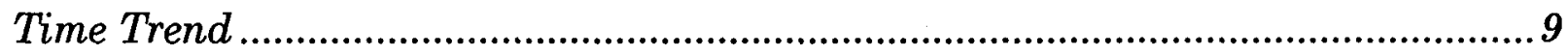

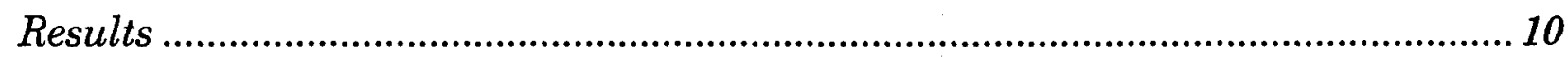

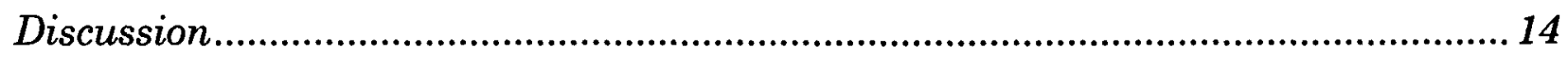

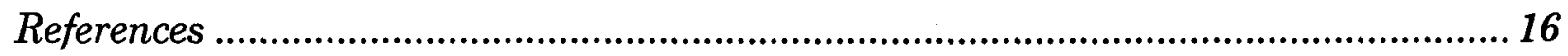

Appendix A: Estimates of Lives Saved by .08 BAC level..........................................19

Appendix B: Treatment Effects for Analysis Without Time Variable..........................20

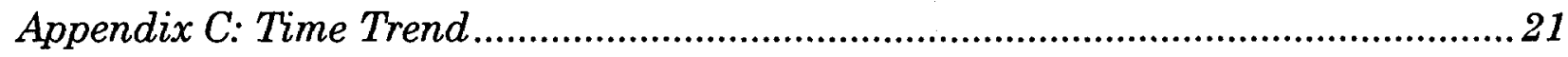




\section{Alcohol Safety Laws and Fatal Crashes}

\section{INTRODUCTION}

The last two decades have seen considerable progress in the passage of alcohol safety legislation. Each of the major pieces of legislation has been evaluated in at least a few states over various periods. This paper evaluates the impact of the major alcohol safety laws over 16 years and includes all 50 states and the District of Columbia. Among the most significant safety policies are laws making a given blood alcohol concentration (BAC) illegal per se. These laws have been enacted in all but two states and, over time, the illegal BAC level has been lowered from .15 to .10 grams per deciliter in most states. In 16 states plus the District of Columbia, the illegal limit has been lowered further to $.08 \mathrm{BAC}$. States with administrative license revocation (ALR) laws have increased from 3 to 40 during this time. Table 1 shows the proportion of the 50 states covered by each law type over the 16-year period from 1982 through 1997 . This purpose of this study was to show the relationship of these laws with the number of alcohol-positive drivers involved in fatal crashes.

TABle 1. Proportion of the population in the 50 STATES and The DISTRICT OF COLUMBIA OPERATING UNDER ALCOHOL SAFETY AND SAFETY BELT LAWS*

\begin{tabular}{|l|l|l|l|l|l|l|}
\hline \multirow{3}{*}{ YEAR } & \multirow{3}{*}{$\begin{array}{l}\text { Admin. } \\
\text { License }\end{array}$} & \multicolumn{3}{l}{ Per se Laws } & \multicolumn{3}{l|}{ Safety Belt Laws } \\
\cline { 3 - 7 } & Revocation & .08 & At least & Secon- & & \\
dary & Primary & Composite \\
\hline 82 & .0588 & .0000 & .3235 & .0000 & .0000 & .0000 \\
83 & .1630 & .0123 & .5490 & .0000 & .0000 & .0000 \\
84 & .3249 & .0392 & .7304 & .0016 & .0016 & .0016 \\
85 & .3824 & .0392 & .7598 & .0736 & .0317 & .0527 \\
86 & .4118 & .0392 & .7843 & .3527 & .1275 & .2401 \\
87 & .4118 & .0392 & .8431 & .4889 & .1373 & .3131 \\
88 & .4608 & .0472 & .8431 & .5947 & .1373 & .3660 \\
89 & .4722 & .0588 & .8627 & .6286 & .1373 & .3830 \\
90 & .5441 & .0784 & .9020 & .6695 & .1385 & .4040 \\
91 & .5784 & .0882 & .9020 & .7450 & 1569 & .4509 \\
92 & .5974 & .0980 & .9412 & .7932 & .1569 & .4750 \\
93 & .6373 & .1127 & .9412 & .8300 & .1765 & .5032 \\
94 & .6766 & .2158 & .9510 & .8989 & .1765 & .5377 \\
95 & .7451 & .2500 & .9608 & .9413 & .1829 & .5621 \\
96 & .7626 & .2745 & .9804 & .9608 & .2059 & .5833 \\
97 & .7843 & .2843 & .9804 & .9640 & .2283 & .5961 \\
\hline
\end{tabular}

* For laws becoming effective part way through the year, state weight was adjusted proportionately to represent time during the year in which the law was in effect.

Fatal crashes result from a multiplicity of factors. Some of the factors that have been shown to affect the number of crashes include amount of travel, the status of the economy, and the quality of vehicles and roadways. Driver alcohol impairment is only one such factor. To properly study the effects of alcohol legislation, it was necessary to control for as many extraneous factors contributing to changes in alcohol-related and non-alcohol-related fatal crash 


\section{Alcohol Safety Laws and Fatal Crashes}

frequency as possible. The most frequently used procedure for studying the legislative impact on crashes is to compare states with and without the stricter BAC laws (for example, see Hingson, Heeren, \& Winter, 1994, 1996; and Johnson \& Fell, 1995). This approach depends upon selecting comparison states similar in significant characteristics to experimental states that have enacted the laws in question. An alternative procedure is a panel study that uses all states over a long time. A state-by-year (or state-by-quarter) matrix can be created as a framework for regression analyses where drinking drivers in fatal crashes constitute the dependent variable and where alcohol safety laws and other factors thought to influence fatal crashes constitute the independent (or "predictor") variables.

To conduct such a study, it is necessary to:

1. identify the dependent variable most relevant to the purposes of the study;

2. identify the laws to be evaluated;

3. identify those additional independent variables that can significantly influence the dependent measure, and

4. provide a trend factor to capture those variables omitted from the analysis.

Figure 1 provides a model of the variables thought to be related to crash causation and included in the current analysis. It illustrates the plan for this study. The relationships shown by the arrows are those studied in the current research. Other potential relationships between those measures were controlled, at least partially, through the regression analyses. 


\section{Alcohol Safety Laws and Fatal Crashes}

FIGURE 1. MODEL FOR ANALYSIS OF THE IMPACT OF LAWS ON THE PROPORTION OF DRIVERS IN FATAL CRASHES WITH BAC >0

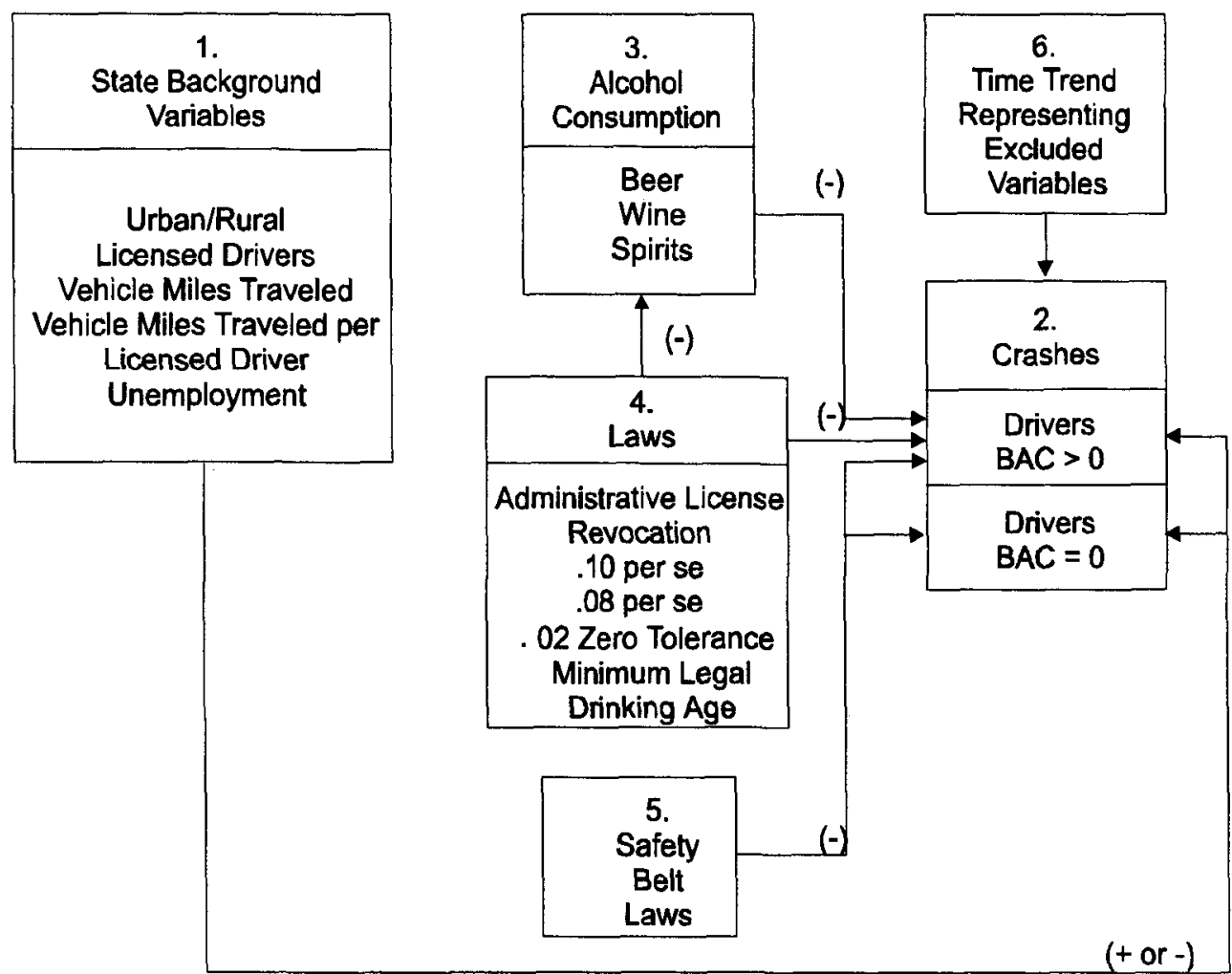

\section{METHODS}

\section{Background variables}

On the left-hand side of Figure 1 are the background factors identified in previous studies to have an influence on the number of fatal crashes in a state. Examples of such factors are the number of licensed drivers, the vehicle miles traveled (VMT), and the unemployment level. Some studies have linked these factors to the total number of crashes but not to alcohol involvement per $s e$. Thus, they should affect equally the numerator and the denominator of the ratio of alcoholpositive to alcohol-negative drivers involved in fatal crashes shown on the right of Figure 1. Measures which are correlated with the number of alcohol-positive drivers involved in fatal crashes include alcohol consumption, anti-drunk driving laws, and safety belt laws, as shown in the center of Figure 1.

\section{The dependent measure}

The Fatality Analysis Reporting System (FARS) for the 50 states and the District of Columbia covering the years 1982 through 1997 provided the dependent measure for the current study. The FARS provides three quantitative measures for the study of fatal crashes: (1) the number of fatal crashes, (2) the number of drivers involved in fatal crashes, and (3) the number of 


\section{Alcohol Safety Laws and Fatal Crashes}

fatalities. Klein (1986) has developed an imputation program for estimating the BACs of drivers in fatal crashes where the actual BAC is unknown. As a result, comparable data on the BAC levels of all drivers involved in fatal crashes are available for all 50 states and the District of Columbia, dating back to 1982 (NHTSA, 1998), and each of the three dependent measures (i.e., number of crashes, drivers, and fatalities) can be related to level of alcohol involvement. Of the 912,954 driver records used in this analysis, 399,348 were fatally injured and $69.2 \%$ of those had known BACs. The remaining 513,606 were surviving drivers of which $23.1 \%$ had known BACs. The Klein procedure provided a probability estimate for the drivers with unknown BACs in three categories: $.00, .01$ to $.09, \geq .10$.

The laws that were studied were aimed at deterring potential drinking drivers. Therefore, it seemed appropriate to "standardize" the dependent measure by using the ratio created by dividing the number of drivers in fatal crashes with a positive BAC by the number of drivers in crashes who had a zero BAC. Using this ratio assists in controlling for those factors that impact all fatal crashes, not just those related to impaired driving. The total amount of driving, as measured by the vehicle miles traveled in a state, for example, is likely to affect both alcohol and non-alcohol-related crashes, presumably to a similar extent. Using this ratio helps to eliminate the effect of this factor, to the extent that miles of driving has a similar effect on alcohol and nonalcohol-related crashes.

\section{Alcohol consumption}

Alcohol consumption potentially has a complex relationship with drinking-and-driving laws. Beer has been shown to be the beverage of choice for individuals convicted of driving while intoxicated (DWI) (Berger \& Snortum, 1985). For this study, separate state per-capita consumption levels were available for wine, beer, and spirits (Williams, Stinson, Sanchez, \& Dufour, 1997). However, only beer and total alcohol consumption correlated significantly with the number of drinking drivers in fatal crashes. Thus, beer consumption was used as the principal relevant measure of alcohol consumption.

The relationship between alcohol consumption, safety legislation, and fatal crashes is complex. It is hypothesized that increased alcohol consumption increases the probability of drivers being involved in an alcohol-related fatal crash. But, it is not clear if decreased consumption has resulted in more alcohol-related safety legislation (and a reduction in alcohol-related fatal crashes) or if such legislation has resulted in a decrease in per-capita consumption.

To determine the direction of this effect, two preliminary analyses were conducted. First, the 1982 annual beer-consumption levels for those states that later adopted .08 laws were compared with consumption levels in those states that, as of 1997, had not enacted such legislation. The average per-capita beer consumption for the $.08 \mathrm{BAC}$ law states was $1.42( \pm .04$ $\mathrm{se})$; the average for the states without $.08 \mathrm{BAC}$ laws was $1.40( \pm .07 \mathrm{se})$. This indicates that there was no significant difference $(p=826)$ in beer consumption between the two groups of states in 1982, prior to the enactment of any .08 BAC laws. Further, an examination of the consumption levels in .08 states, by date of adoption, indicated that the early adopters did not have different levels of per-capita beer consumption than late adopters $(p=311)$. A second study compared per- 


\section{Alcohol Safety Laws and Fatal Crashes}

capita beer consumption before-versus-after the enactment of .10 BAC, .08 BAC, and ALR laws in states that adopted such legislation. For all three laws, there was a reduction in beer consumption following the enactment of the law. The reduction associated with 10 per se was $3.22 \%$; the reduction associated with .08 per se was $3.49 \%$; and the reduction associated with ALR was $2.16 \%$. All of these differences were significant $(p<.001)$. Thus, the evidence examined in this study favors the hypothesis that the relationship between the safety laws and beer consumption is that the laws affect consumption, rather than the other way around.

\section{Drinking-and-driving laws}

The independent variables of interest in this study were three important drinking-anddriving laws enacted over the 16 years (1982 to 1997) since reliable BAC data became available in the FARS. The three laws were the ALR laws; .10 BAC (illegal per se) laws; and .08 BAC (illegal per se) laws. All three laws have been associated with reductions in alcohol-related fatal crashes in one or more studies over the last two decades but there has been some recent controversy regarding the impact of $.08 \mathrm{BAC}$ laws.

\section{(a) Administrative license revocation laws}

The District of Columbia and 40 of the 50 states now have laws that administratively suspend or revoke the driver licenses of offenders who fail a breath test (i.e. their breath samples are above the legal limit). The evidence for the effectiveness of these laws is quite strong. Two studies (Zador, Lund, Field, \& Weinberg, 1988; Klein, 1989) have demonstrated that ALR laws have a general deterrent effect in that they have resulted in reductions in alcohol-related fatal crashes. Two recent studies (Voas, Tippetts, \& Taylor, 1999; Beirness, Simpson, Mayhew, \& Jonah, 1997) have shown that ALR laws also have a specific deterrent effect (i.e., they reduce DWI recidivism among offenders whose licenses have been suspended or revoked due to an ALR law). Thus, it has been commonly accepted that ALR laws have both specific and general deterrent effects. Wagenaar, Zobeck, Hingson, and Williams (1995) reviewed 12 studies on administrative license revocation as part of a meta-analysis of literature on the effects of DUI control efforts. They found a reduction of $5 \%$ for alcohol-related fatal crashes and $5 \%$ for nighttime fatal crashes, a surrogate measure of alcohol-related crashes.

\section{(b) .10 BAC illegal per se laws}

All but two states, Massachusetts and South Carolina, have enacted illegal per se BAC laws. Such laws make it illegal per se to drive or to be in actual physical control of a vehicle while having a BAC over a specified limit. The first such law was enacted in Nebraska in 1963. By 1982, a third of the states had such laws and, two years later, three out of four states had illegal per se laws. Thus, most of the impact of this legislation occurred in the early period of this study. In a study of laws passed between 1978 and 1985, Zador and colleagues (1988) found that illegal per se BAC laws were associated with a $2 \%$ reduction in fatal crashes. As part of a metaanalysis of alcohol safety law research studies conducted between 1960 and 1991, Wagenaar, Zobeck, Hingson, and Williams (1995) reviewed nine studies regarding the impact of illegal per se 


\section{Alcohol Safety Laws and Fatal Crashes}

laws relative to alcohol-related fatal crashes and nighttime fatal crashes. The impact of these laws, relative to these two measures, was estimated to be minus $2 \%$ and minus $3 \%$, respectively.

\section{(c) .08 illegal per se laws}

Most industrialized nations have BAC limits of .08 (e.g., Britain and Canada) or .05 (e.g., in Europe and Australia). Legislation that would lower the illegal per se BAC level to 0.08 in the U.S. has received much recent attention from safety advocacy groups. Research supporting the appropriateness of lower BAC limits is strong. A review by Moskowitz, Burns, and Williams (1985) demonstrated that alcohol impairment for many people begins at as low as .02 BAC. Analyses of roadside surveys and crash data by Zador (1991) and Hurst (1973) have shown that, at a BAC of .05 or greater, the risk of involvement in an alcohol-related fatal crash increases significantly. There have been several studies of the effectiveness of such legislation but they have been limited by the relatively few states that have enacted .08 BAC laws. An early study conducted in California (NHTSA, 1991), found a 12\% reduction in alcohol-related crashes due to the combined effect of .08 BAC and ALR laws, enacted within 6 months of each other. Rogers (1997) in a study of the .08 BAC law in California found a relatively modest $7 \%$ effect on nighttime crashes occurring between $12 \mathrm{AM}$ and 2 AM. Johnson and Fell (1995) reported that four out of five states (California, Maine, Oregon, Utah, and Vermont) implementing .08 BAC laws showed significant reductions in one or more measures of alcohol-related fatal crashes. A study by Hingson and colleagues (1996), which was limited to five states with such legislation and a somewhat controversial selection of five comparison states, found that .08 BAC laws were associated with a significant reduction in the proportion of drivers in fatal crashes who had BACs greater than .08. That study also showed a significant reduction in the proportion of high BAC drivers involved in fatal crashes (i.e., at or above .15 BAC). However, these results were affected by the fact that these states had also recently enacted ALR legislation.

\section{Safety belt laws}

Occupant restraint programs include three types of laws: child safety seat laws, secondary safety belt laws, and primary (also known as standard) safety belt laws. Secondary laws require the observation of some other traffic offense before a driver can be stopped and cited for nonuse of a safety belt. Primary laws allow an officer to stop and cite the driver based solely on a safety belt violation. Since this study focuses on alcohol use by drivers, child safety seat laws were not included. NHTSA estimates that safety belts have saved 100,000 lives since 1975 (NHTSA, 1997).

Use of safety belts has a complex relationship with alcohol-related crashes. Clearly, usage protects both drinking and nondrinking drivers. However, the usage rates among these two driver groups varies significantly and, depending upon the level of usage, a law requiring usage will affect drinking and nondrinking drivers differently. In the absence of safety belt use laws, safety belt usage is lower among drinking drivers than among nondrinking drivers, but the usage rates of both groups is low. In such a situation, the effect of enacting a safety belt use law generally produces proportionally greater usage among nondrinking drivers than among drinking drivers. At higher usage rates, however, where the use rates of nondrinking drivers are already much higher than those of drinking drivers, an upgrade in the law (which usually makes it more enforceable) is 


\section{Alcohol Safety Laws and Fatal Crashes}

likely to affect drinking drivers to a greater degree than nondrinking drivers since their usage rate is so much lower (Voas \& Tippetts, 1998).

Thus, initial safety belt laws (enacted when safety belt use rates are quite low) are likely to increase the ratio of alcohol-positive to alcohol-negative drivers involved in fatal crashes. When upgrades in safety belt laws occur (usually when usage rates are much higher), a larger proportion of alcohol-positive drivers than alcohol-negative drivers will begin to use safety belts (making them less likely to be involved in a fatal crash). Thus, at this level, it is hypothesized that such laws will reduce the alcohol-positive to alcohol-negative ratio of drivers involved in fatal crashes.

Because some states moved directly to primary laws while others first passed secondary laws, attempts in the present research to use two separate variables to represent these laws were complicated by the varying sequence in the enactment of these measures. Ultimately, it was decided to represent secondary and primary safety belt laws with a single three-level variable, with values of zero, 0.5 , and one. Primary safety belt laws are weighted twice as effective (value $=1$ ) as secondary laws (value $=0.5$ ). This estimate is based on the fact that initial increases in safety belt usage rates were significantly greater in primary law states than in secondary law states. Furthermore, in recent years when several states have upgraded from secondary to primary laws, significant increases in usage have been observed. Prior to any safety belt use laws, the national usage rate stood at approximately $14 \%$. By 1994, the average usage rate in no law, secondary law, and primary law states was $45 \%, 62 \%$, and $75 \%$, respectively (NHTSA, 1995).

\section{ANALYSIS}

To evaluate the effects of ALR, .10 and .08 per se laws, FARS data were analyzed using weighted least squares (WLS) regression models. The ratios of alcohol-involved drivers to nonalcohol-involved drivers are aggregated into a two-way 'matrix' by state, and within state, by period (i.e., by quarter or by year). Using this ratio controls for general driving and safety trends by reducing the need for covariates that predict fatal crashes. It also controls for differences among states in size. Further, this ratio was transformed using a natural logarithm to make the coefficients for the laws' effects readily interpretable for the percentage of increase or decrease. This transformation also improves the normality of the distribution of the dependent variable, thus making statistical assumptions more confident and the model less susceptible to spurious findings resulting from undue influence of outliers.

Drinking and driving by individuals under age 21 is affected by two important laws not included in this analysis: the age-21 drinking limit and the "zero tolerance" (.02 BAC limit for drivers under age 21). Because these laws are expected to affect the youth and not adult age groups, this study was limited to drivers age 21 and over. The impact of the age- 21 and zero tolerance laws are the topic of a separate paper. The FARS BAC imputation system (Klein, 1986) classifies crash-involved drivers into three $\mathrm{BAC}$ categories: $\mathrm{BAC}=0, \mathrm{BAC}=.01-.09$, and $\mathrm{BAC}=\geq .10$. There is considerable controversy over whether lowering the BAC limit to .08 will affect high BAC offenders (.10+) as well as low BAC offenders (.08 to .09). Consequently, in analyzing the three alcohol safety laws, the cases were analyzed in two groups:

Group 1-drivers in fatal crashes with measured or imputed BACs from .01 to .09; 


\section{Alcohol Safety Laws and Fatal Crashes}

Group 2-drivers in fatal crashes with measured or imputed BACs .10 or greater.

The drivers' data were aggregated quarterly within years (Jan-Mar, Apr-Jun, Jul-Sept, Oct-Dec), resulting in 64 data points for each state and the District of Columbia, for a total of $3,264$ ( $64 \times 51)$ data points. In each period, two ratios were calculated with the numerator equal to: (1) the number of drivers measured/imputed to have BACs in the $.01-.09$ range, with the denominator the number of drivers measured/imputed to be alcohol-negative, and (2) the number of drivers measured/imputed to have BACs 2.10 , with the same denominator. Drivers without a measured and, therefore known, BAC had an imputed probability of being alcohol-positive and another imputed probability of being alcohol-negative; for these drivers, the probabilities were used as fractional case weights in the aggregation process.

\section{Weighting}

We used WLS regression models, weighting the cases for some states more than for others because the data for the more populous states are generally more stable (i.e., contain less sampling error) than data from smaller states. This occurs because a large state's pool of crashinvolved drivers in any given year (or month) is a much larger sample. This weighting, therefore, makes it less susceptible to fluctuation resulting from random factors. For example, the difference of one or two cases per month in a smaller state can produce large differences in the state's ratio.

Case weights were determined by using bootstrap re-sampling procedures to estimate the sampling variability within each state per period (year or quarter). Within-state variability to a great extent is caused by the sampling size of the state's pool of crashes and, therefore, taps into the size-of-state dimension well (Spearman's rho=.858). In addition, the weighting derived from within-state variability has the desirable qualities of a narrower range and a less extreme distribution. Larger states have lower re-sampling variability because they have more crashinvolved drivers and random fluctuations tend to wash out, thereby providing more reliable ratios. Weighting cases by this measure naturally places more importance on the experience of larger states or at least on those states having a larger traffic problem in terms of numbers of fatal crashes. These case weights had a mean of 1.0 across all 51 states (including the District of Columbia) within each period, ranging from a low of approximately 0.25 (North Dakota, Alaska, and Rhode Island) to a high of slightly more than 2.5 (California).

\section{Independent Variables and Covariates}

The three alcohol-related laws being evaluated were modeled as dichotomous dummy variables: When a law became effective partway through a quarterly period, the variable represented that portion of the quarter the law was in effect. When a state lowered its per se limit from .10 to .08 , the dummy variable for the per se .10 law was continued so as to ensure that the dummy variable for the .08 law represented only the marginal effect of the lowered limit. Safety restraint laws were modeled as a single three-step variable, with no law represented by a value of zero, a secondary law represented by a value of 0.5 , and a primary law represented by 1.0 .

Maryland and Massachusetts enacted ALR laws embodying a BAC limit without establishing a per se law. Since the ALR limit may have a greater impact in terms of certainty of 


\section{Alcohol Safety Laws and Fatal Crashes}

sanctioning, these two states were modeled as having the corresponding per se law BAC limit when they enacted their ALR law. In all other states, the per se laws were passed first and then strengthened by the later passage of the ALR.

To avoid over-fitting a model with a dummy parameter for each state and to explain variation over time within states, other variables relating to state environment and conditions were used as covariates. The most important of these in terms of correlating with the prevalence of alcohol in drivers involved in fatal crashes was per-capita beer consumption. Consumption data were not yet available for 1996 and 1997, the two years when many of these laws were enacted. So, rather than eliminate one of the strongest predictors of alcohol-involved crashes, a per-state average beer consumption level, a between state measure that was constant over time within each state, was developed.

As reported earlier in this paper, per-capita alcohol consumption differences between states were unrelated to passage of DWI laws. However, these differences might still be related to the number of drinking drivers in crashes. Where small, but significant, effects of the safety laws on increasing subsequent consumption within states were found, state consumption levels were adjusted for the laws' effects on drinking for those states passing the laws. After averaging the adjusted beer consumption level for each state, this variable served as a between-state covariate only, remaining constant over time within each state.

Among other measures that vary between-states within the same period and within-states over time, three were found to be important predictors: per-capita vehicle miles traveled (VMTPC) changed yearly, urban/rural distribution of the state's population changed yearly, and unemployment rates changed quarterly. The two components of VMTPC - total state VMT and number of licensed drivers-could have been used in the model. However, since our dependent variable is a rate and, therefore, already standardized by state size (by dividing the numerator by the number of non-alcohol-related drivers in that state), the observed nonsignificance of these measures was anticipated.

For these analyses for which our data were quarterly ratios, we also regressed out seasonal factors globally by using a dummy variable for three of the four quarters. Only two of these- the spring and summer quarters-were significant, with the fall quarter not being significantly different from the winter quarter.

An issue in studies of this type is whether states with lower numbers of alcohol-related crashes are more likely to pass safety legislation. This could account for any observed relationships between the three alcohol safety laws and drinking drivers in crashes. To account for any such original differences in alcohol-related crash frequency, a factor designated by the \# sign was entered into the study for those states that passed such laws at some point during the 16 years covered by the study. These factors included administrative license revocation (ALR\#), per se .10 (PS\#.10), per se .08 (PS\#08) and safety belt (SB\#) laws.

\section{Time Trend}

The model in Figure 1 provides for a time trend variable to capture the variance of unmeasured causative factors which change systematically over time and may influence the 


\section{Alcohol Safety Laws and Fatal Crashes}

proportion of drivers in fatal crashes who have been drinking. Examples of such a factor is the possibility that a growth in the proportion of females or in the elderly (who consume lower amounts of alcohol) among the driving population reduce the proportion of drinking drivers in fatal crashes. To capture the influence of such factors, a quadratic trend factor was regressed on the 64 quarterly drinking-drivers-in-fatal-crash ratios, separately for the .01 to .09 group and the .10 or greater group. While the entry of this quadratic trend into the analysis increases the amount of explained variance (by $20 \%$ for the $.01-.09$ group; by $40 \%$ for the .10 or greater group), it also potentially captures some of the valid effects of the three alcohol safety laws since these became effective over time (see Table 1). Since the correlations between the quadratic trend and the three laws varied between -.30 and -.40 , the effect sizes produced by the trend-adjusted analysis should be conservative.

\section{RESULTS}

Table 2 provides the results of the analysis for drivers with BACs between .01 and .09 , while Table 3 provides the results for the analysis of those drivers in fatal crashes with a BAC of .10 or greater. With respect to the three alcohol safety laws of interest-ALR, .10 per se, and .08 per se-there was a significant negative relationship between the presence of each of these laws and the proportion of drivers who had been drinking in fatal crashes. The effect of the year trend varied between the two groups. For the drivers with BACs at or above .10, the trend was, clearly, curvilinear, as indicated by the significance of both the YR2 TREND and the YR_TREND factors. In contrast, only the YR2 TREND was significant for the drivers in the .01 to $.09 \mathrm{BAC}$ range, indicating that in this case the time trend represented more of a linear reduction in drinking drivers across the 16 years of the study. In both cases, as would be expected, the year trend was correlated with a reduced proportion of drinking drivers in fatal crashes. This is consistent with the downward trend in alcohol-related crashes reported in FARS Annual Reports over that period. Note, that this reduction is in addition to the reductions associated in each table with the three laws of interest: ALR, $10 \mathrm{BAC}$, and $.08 \mathrm{BAC}$. 


\section{Alcohol Safety Laws and Fatal Crashes}

TABLE 2. VARIABLES SIGNIFICANTLY RELATED TO THE PROPORTION OF DRINKING DRIVERS IN FATAL CRASHES WITH BACS BETWEEN .01 AND .09

\begin{tabular}{|c|c|c|c|c|c|c|c|}
\hline & \multirow[b]{2}{*}{ B } & \multirow[b]{2}{*}{ Std. Error } & \multirow[b]{2}{*}{ Beta } & \multirow[b]{2}{*}{$t$} & \multirow[b]{2}{*}{ Sig. } & \multicolumn{2}{|c|}{ Correlations } \\
\hline & & & & & & Zero-order & Partial \\
\hline (Constant) & -4.78598 & .146 & & -32.737 & .000 & & \\
\hline BEER@ADJ & .58444 & .053 & .191 & 11.062 & .000 & 195 & 190 \\
\hline UE@ & .01025 & .005 & .036 & 2.062 & .039 & .138 & .036 \\
\hline ALR@ & -.21021 & .027 & -.169 & -7.764 & .000 & -.227 & -.135 \\
\hline PS@10 & -.14125 & .028 & -.087 & -5.031 & .000 & -.126 & -.088 \\
\hline PS@08 & -.08224 & .041 & -.041 & -2.019 & .044 & -.154 & -.035 \\
\hline YR2TREND & -.0000851765 & .000 & -.166 & -8.095 & .000 & -.256 & -.141 \\
\hline QTR2 & .17652 & .023 & .124 & 7.597 & .000 & .082 & .132 \\
\hline QTR3 & .21376 & .023 & .150 & 9.200 & .000 & .099 & .159 \\
\hline VMT@ & .10899 & .013 & .156 & 8.153 & .000 & .183 & 142 \\
\hline SB\# & .11198 & .022 & .085 & 5.016 & .000 & .132 & .088 \\
\hline URBAN & .49323 & .082 & .112 & 6.016 & .000 & .213 & .105 \\
\hline ALR\# & 15287 & .031 & .105 & 4.954 & .000 & .033 & .087 \\
\hline PS\#08 & -.06672 & .027 & -.050 & -2.465 & .014 & -.026 & -.043 \\
\hline
\end{tabular}

Multiple R's-Without trend component: .443; with trend component: .484

TABLE 3. VARIABLES SIGNIFICANTLY RELATED TO THE PROPORTION OF DRINKING DRIVERS IN FATAL CRASHES WITH BACS AT OR ABOVE .10

\begin{tabular}{l|c|c|c|c|c|c|c}
\hline & & & & & & \multicolumn{2}{|c}{ Correlations } \\
\cline { 5 - 8 } & $\mathrm{B}$ & Std. Error & Beta & $\mathrm{t}$ & $\mathrm{Sig}$ & Zero-order & Partial \\
\hline (Constant) & -2.39975 & .072 & & -33.150 & .000 & & \\
BEER@ADJ & .63269 & .031 & .303 & 20.687 & .000 & .258 & .341 \\
VMTPERLD & .04778 & .004 & .233 & 13.054 & .000 & -.111 & .223 \\
UE@ & .01546 & .003 & .080 & 4.681 & .000 & .226 & .082 \\
ALR@ & -.13708 & .014 & -.162 & -9.489 & .000 & -.258 & -.164 \\
PS@10 & -.09090 & .018 & -.081 & -4.979 & .000 & -.219 & -.087 \\
PS@08 & -.08340 & .025 & -.062 & -3.334 & .001 & -.243 & -.058 \\
YR2TREND & -.0000889403 & .000 & -.254 & -4.266 & .000 & -.442 & -.075 \\
YR_TREND & -.0050083072 & .002 & -.220 & -3.295 & .001 & -.441 & -.058 \\
QTR2 & .11763 & .015 & .121 & 8.080 & .000 & .090 & .140 \\
QTR3 & .11648 & .015 & .120 & 8.003 & .000 & .069 & .139 \\
SEATBELT & .09460 & .023 & .078 & 4.201 & .000 & -.242 & .073 \\
PS\#08 & .04869 & .015 & .054 & 3.141 & .002 & -.023 & .055 \\
\hline
\end{tabular}

Multiple R's—Without trend component: .502; with trend component: .594

For both analyses, the adjusted beer consumption factor (BEER@ADJ) was correlated with an increased number of drinking drivers in fatal crashes. This factor represents the difference between states in beer consumption, not a change in sales over time within-state, since our preliminary study indicated that beer consumption fell following the passage of alcohol safety legislation. As previously noted, to avoid contamination with the alcohol legislation, the beer consumption value was adjusted for those states that did pass alcohol legislation so that the average value per state remained constant through the analysis period. The analysis indicates that 


\section{Alcohol Safety Laws and Fatal Crashes}

states with higher beer consumption had more alcohol-related crashes as suggested by the model in Figure 1.

In both the .01 to .09 and the $.10+$ analyses, the seasonally weighted unemployment variable was correlated with a higher proportion of drinking drivers in fatal crashes suggesting increased impaired driving in states with high unemployment, relative to other states. In both analyses, the spring and summer quarters were associated with a higher proportion of drinking drivers in fatal crashes. This is in keeping with studies that have found proportionately more alcohol-related crashes in the summer months.

In both analyses, the PS\#.08 factor for the states that passed a $.08 \mathrm{BAC}$ law during the 16 years of the study was significant. It had small correlations with reduced proportions of drinking drivers in fatal crashes. This relationship is, of course, in addition to the relationship shown for the dummy variable for the $.08 \mathrm{BAC}$ law itself.

Table 4 provides the effect sizes based on the natural log of the dependent measure (the ratio of drivers in fatal crashes with .01 to .09 or .10 or greater BACs over drivers in fatal crashes with zero BACs).

TABLE 4. EFFECT SIZES FOR ALCOHOL SAFETY AND SAFETY BELT LAWS FOR TWO GROUPS OF DRIVERS IN FATAL CRASHES

\begin{tabular}{c|l|l}
\hline \multirow{2}{*}{ Alcohol Safety Laws } & \multicolumn{2}{|l}{ Drivers in fatal crashes age 21 and older } \\
\cline { 2 - 3 } & Estimates & $95 \%$ confidence interval \\
\hline Illegal per se laws (.10) & & \\
.01 to .09 & $-13.17 \%$ & $-8.26 \%$ to $-17.82 \%$ \\
$.10+$ & $-8.69 \%$ & $-5.36 \%$ to $-11.90 \%$ \\
Per se 08 law & & \\
.01 to .09 & $-7.89 \% *$ & $-0.24 \%$ to $-14.96 \%$ \\
$.10+$ & $-8.00 \%$ & $-3.38 \%$ to $-12.40 \%$ \\
Admin. license revocation law & & \\
.01 to .09 & $-18.96 \%$ & $-14.54 \%$ to $-18.96 \%$ \\
$.10+$ & $-12.81 \%$ & $-10.31 \%$ to $-15.24 \%$ \\
\hline
\end{tabular}

* Significant at $p=.05$; all other significant at $p<.001$

Interpreting effects sizes: The effect sizes shown in Table 4 are somewhat difficult to interpret because they are percentages of ratios. Further, they are not additive because they are expressed as percentages. Rather, they are multiplicative. This means that the total percentage reduction attributable to a combination of two or more laws is slightly less than it would be if the percentages were simply added together. Thus, two or more of the laws studied account for some involvement of the same drivers. To make these effect sizes more meaningful, the impact of a single law on fatalities can be estimated using the following assumptions and procedures.

The first assumption is that since this analysis included only adult drivers ( 21 years and older), the calculation assumes that zero lives were saved by a reduction in crashes involving drivers under age 21 . Further, the analyses conducted were based on drivers involved in fatal crashes, not on the number of fatalities. The estimated reductions due to the 08 BAC law "effect" were $7.8 \%$ fewer drivers at .01-.09 BAC, and 8\% fewer drivers at .10+ BAC. After calculating the number of drivers these percentage reductions represent, that figure is converted into the 


\section{Alcohol Safety Laws and Fatal Crashes}

number of fatalities that would have been associated with those drivers. ${ }^{1}$ The conversion rates, calculated from the 1997 FARS data, were .9222 fatalities per driver at $.10+\mathrm{BAC}, .8332$ fatalities at $.01-.09 \mathrm{BAC}$, and .6901 fatalities at $.00 \mathrm{BAC}$.

To arrive at these conversion "rates," the drivers involved in each crash are divided into three BAC categories based upon the driver-level Klein imputations (.00 BAC, .01-.09, .10+). The total fatalities within each crash are then attributed proportionately to each of the three BAC categories of drivers involved in that crash. For example, if there were four fatalities in a crash involving three drivers, and two of the three drivers were in the $.10+$ category, with the other driver alcohol-negative, then $2 / 3$ of the 4 fatalities ( 2.667 fatalities) would be attributed to drivers at the $.10+$ level, and $1 / 3$ of the fatalities (1.333 fatalities) would be attributed to the driver at the .00 level. This proportional attribution of involvement to drivers implies equal responsibility for the crash to each driver, regardless of BAC level, and ignores the possibility of one or more drivers being more at fault than others. As such, this approach probably underestimates the number of fatalities that alcohol-positive drivers are responsible for, given that these drivers are more likely to be at fault. In the (mathematically) trivial case of single vehicle crashes, the proportional involvement and fault are, with very few exceptions, identical. This procedure yielded the estimate that if, rather than 15 states, all 50 states had .08 laws throughout 1997, 590 ( $95 \%$ confidence interval=200 to 958 ) additional lives would have been saved. The .08 and .10 illegal per se laws are shown in Table $5 .^{2}$

1 Note that for the 122 crashes with no known driver (i.e., no person type=1), the crash level BAC imputation was used to attribute fatalities to the three involvement categories.

2 For individual state estimates, see Appendix $A$. 
TABLE 5. ESTIMATED SAVINGS IN 1997 FOR THE THREE ALCOHOL SAFETY LAWS ANALYZED IN THIS STUDY

\begin{tabular}{llll}
\hline & .08 per se & .10 per se & ALR \\
\cline { 2 - 4 } States with law in 1997 & 16 & $49 \& \mathrm{DC}^{*}$ & 39 \& DC \\
Estimated to have been & 275 & 1,115 & 1,359 \\
saved in states with & $95 \%$ confidence & $95 \%$ confidence & $95 \%$ confidence \\
laws in 1997 & interval & interval & interval \\
& 88 to 472 & 663 to 1,586 & 1,040 to 1,690 \\
Estimated additional & 590 & 18 & 335 \\
savings had all states & $95 \%$ confidence & $95 \%$ confidence & $95 \%$ confidence \\
had laws in 1997 & interval & interval & interval \\
& 200 to 958 & 11 to 24 & 266 to 402 \\
\hline
\end{tabular}

Massachusetts counted as .08 because of .08 ALR law. South Carolina only non-. 10 state

\section{Discussion}

A critical issue for regression studies of this type is the direction of effect among alcohol consumption, alcohol safety legislation, and alcohol-related crashes. Our preliminary analysis suggested that consumption was not a factor in the passage of safety legislation but that there was a small relationship between the proportion of drinking drivers in fatal crashes in a state and the probability that it would pass a .08 BAC law. On the other hand, we found that beer consumption was lower following the passage of alcohol legislation. Finally, this study provides clear evidence that states with higher beer consumption have higher proportions of drinking drivers in fatal crashes. In contrast, passage of alcohol safety legislation is associated with lower proportions of drinking drivers. Further analysis using structural equation modeling among other techniques will be required to fully explore these relationships between beer consumption, laws, and alcoholrelated crashes.

This study has a weakness inherent in all regression analyses; the validity relies on the extent to which all significant predictors of the dependent variable have been accounted for in the analysis. In the present case, the national norms regarding drinking and driving may have changed, which is an underlying factor in both the passage of alcohol safety legislation and the number of drinking drivers involved in fatal crashes. There is strong evidence that such a normative change has occurred since 1980. This is about that time when several citizen activist groups-Remove Intoxicated Drivers (RID), Mothers Against Drunk Driving (MADD), Students Against Drunk Drivers (SADD), etc. - were founded (McCarthy \& Harvey, 1988). Increased activism and research interest by local, state, and federal governments led to a large increase in press coverage of the drinking-and-driving issue and a flood of new alcohol safety legislation. This study did not include any measure of media coverage of the drinking-and-driving issue or any measure of public attitudes toward drinking and driving, since such a measure was not available by year and state during the period of this study. Possibly, the public's attention to the drinking-and-driving issue is producing both the laws and the reduction in drinking drivers in fatal crashes. However, it has generally been found that media campaigns in the absence of newly institutionalized actions (such as legislation) do not produce measurable reductions in crash frequencies (Wilde, Hoste, Sheppard, \& Wind, 1971). 


\section{Alcohol Safety Laws and Fatal Crashes}

This study attempted to minimize the need for a time variable by including in the model potentially confounding, non-law measures such as VMT and employment and alcohol consumption. Further, the use of the ratio of drinking to nondrinking drivers as a criterion measure, ensures that those factors that affect all fatal crashes, drinking and nondrinking alike, should have little affect on the dependent measure. Thus, the effect sizes obtained in this analysis are probably conservative. The results shown in Appendix B provide some insight as to how much the use of the time variables may have affected the results.

In a further effort to account for these longer term unmeasured effects, a time variable was entered into the present analysis. This factor accounted for some additional variance raising the $\mathrm{R}$ of the analysis of .10 drivers from .50 to .59 . At the same time, this trend variable probably absorbed some of the true effects of the three alcohol safety laws. This provides another indicator that the effect sizes shown in Table 4 are probably conservative.

This study is not the first to produce evidence for the effectiveness of the three laws included in the analysis. However, this study covers the longest period (16 years) and more states (all 50 plus the District of Columbia) than most previous studies. It also specifically includes potentially confounding variables such as alcohol consumption and safety belt laws not directly considered in most previous studies. The credibility of the results is strengthened by their conformity to theoretical expectations. Beer consumption, for example, is associated with proportionally more positive BAC drivers in fatal crashes as would be expected. Furthermore, the relationships between alcohol safety laws and reductions in drinking-driver involvements, while significant, are generally consistent with the results of other studies.

Perhaps, more significant than the effect of any one law is the evidence that each of these major alcohol-safety laws has contributed to the downward trend over the last two decades of alcohol-related crashes. As should be expected, this long-term national trend is not the product of any single policy act, and it is undoubtedly influenced by factors not in the present analysis such as the increasing use of sobriety checkpoints in some states. Since factors such as alcohol policies, roadway and vehicle characteristics, and economic conditions all interact in their influence on crashes, it is important to interpret estimates of lives saved due to any single law with considerable caution. 
Alcohol Safety Laws and Fatal Crashes

\section{REFERENCES}

Beirness, D. J., Simpson, H. M., \& Mayhew, D. R. (1993). Predicting crash involvement among young drivers. In H.-D. Utzelmann, G. Berghaus, \& G. Kroj (Eds.). Alcohol, Drugs and Traffic Safety - T92. Proceedings of the 12th International Conference. (pp. 885-890). Cologne, Germany: Verlag TUV Rhineland.

Beirness, D. J., Simpson, H. M., Mayhew, D. R., \& Jonah, B. J. (1997). The impact of administrative license suspension and vehicle impoundment for DWI in Manitoba. In C. Mercier-Guyon (Ed.) Proceedings of the 14th International Conference on Alcohol, Drugs and Traffic Safety. (pp. 919-925). Annecy, France: Centre d'Etudes et de Recherches en Medecine du Trafic.

Berger, D. E., \& Snortum, J. R. (1985). Alcoholic beverage preference of drinking-driving violators. Journal of Studies on Alcohol, 46(3), 232-239.

Blomberg, R. (1992). Lower BAC limits for youth: Evaluation of the Maryland .02 law. (DOT HS 806 807). Washington, DC: U.S. Department of Transportation.

General Accounting Office (USGAO). (1987, March). Drinking-age-laws: An evaluation synthesis of their impact on highway safety. (GAO/PEMD-87-10). Washington, DC: USGAO.

Hingson, R. (1996). Prevention of drinking and driving. Alcohol Health \& Research World, 20(4), 219-226.

Hingson, R., Heeren, T., \& Winter, M. (1994). Lower legal blood alcohol limits for young drivers. Public Health Reports, 109(6), 739-744.

Hingson, R., Heeren, T., \& Winter, M. (1996). Lowering state legal blood alcohol limits to 0.08 percent: The effect on fatal motor vehicle crashes. American Journal of Public Health, 86, $1297-1299$.

Hurst, P. (1973). Epidemiological aspects of alcohol in driver crashes and citations. Journal of Safety Research, 5(3), 130-148.

Johnson, D., \& Fell, J. (1995). The impact of lowering the illegal BAC limit to .08 in five states in the U.S. In 39th Annual Proceedings for the Association for the Advancement of Automotive Medicine, October 16-18, 1995. Chicago, IL. pp. 45-64.

Klein, T. (1986, July). A method for estimating posterior BAC distributions for persons involved in fatal traffic accidents. (DOT HS 807 094). Washington, DC: National Highway Traffic Safety Administration.

Klein, T. (1989). Changes in alcohol-involved fatal crashes associated with tougher state alcohol legislation. (Final Report under Contract No. DTNH-122-88-C-07045). Washington, DC: National Highway Traffic Safety Administration.

Lange, J. E., \& Voas, R. B. (1998). Nighttime observations of safety belt use: An evaluation of California's primary law. American Journal of Public Health, 88(11), 1718-1720. 


\section{Alcohol Safety Laws and Fatal Crashes}

McCarthy, J. D., \& Harvey, D. S. (1988). Independent citizen advocacy: The past and the prospects. In Surgeon General's workshop on drunk driving: Background papers. (pp. 247-260). Washington, DC: U.S. Department of Health and Human Services, Public Health Service, Office of the Surgeon.

Moskowitz, H., Burns, M. M., \& Williams, A. F. (1985). Skills performance at low blood alcohol levels. Journal of Studies on Alcohol, 46(2), 482-485.

National Highway Traffic Safety Administration. (1991). The effects following the implementaiion of an 0.08 BAC limit and an administrative per se law in California. (Report No. DOT HS 807 777). Washington, DC: National Highway Traffic Safety Administration.

National Highway Traffic Safety Administration. (1994). Traffic safety facts 1994. Washington, DC: National Highway Traffic Safety Administration.

National Highway Traffic Safety Administration. (1995). National Safety Belt Usage Rages: A Population-Weighted Aggregate of State Reported Usage. Traffic Safety Programs. Washington, DC: National Highway Traffic Safety Administration.

National Highway Traffic Safety Administration (NHTSA). (1997). Traffic Safety Facts 1997 Occupant Protection. (DOT HS 808 768). Washington, DC: NHTSA, National Center for Statistics \& Analysis, Research \& Development.

National Highway Traffic Safety Administration. (1998). Fatality Analysis Reporting System data files, 1982-1997. Washington, DC: NHTSA National Center for Statistics and Analysis.

Rogers, P. N. (1997). The specific deterrent impact of California's 0.08\% blood alcohol concentration limit and administrative per se license suspension lows. (Vol. 2).

Sacramento, CA: Research and Development Branch, Licensing Operations Division, California Department of Motor Vehicles and Office of Traffic Safety.

Toomey, T. L., Rosenfeld, C., \& Wagenaar, A. C. (1996). The minimum legal drinking age: History, effectiveness, and ongoing debate. Alcohol Health \& Research World, 20(4), 213218.

Voas, R. B., Lange, J. E., \& Tippetts, A. S. (1999, in press). Enforcement of the zero tolerance law in California: A missed opportunity? Journal of Crash Prevention and Injury Control.

Voas, R. B., Tippetts, A. S., \& Taylor, E. P. (1999, in press). Impact of Ohio administrative license suspension. Journal of Crash Prevention and Injury Control.

Wagenaar, A. C. (1993). Minimum drinking age and alcohol availability to youth: Issues and research needs. In M. E. Hilton \& G. Bloss (Eds.). Economics and the prevention of alcohol-related problems. (Research Monograph No. 25, NIH Pub. No. 93-3513, pp. 175200). Bethesda, MD: National Institute on Alcohol Abuse and Alcoholism.

Wagenaar, A. C., Zobeck, T. S., Hingson, R., \& Williams, G. D. (1995). Studies of control efforts: A meta-analysis from 1960 through 1991. Accident Analysis and Prevention, 27, 1-16. 


\section{Alcohol Safety Laws and Fatal Crashes}

Wilde, C. J. S., Hoste, J. L., Sheppard, D., \& Wind, G. (1971). Road safety campaigns: Design and evaluation. Organization for Economic Co-operation and Development, 75.

Williams, J. D., Stinson, F. S., Sanchez, L. L., \& Dufour, M. C. (1997, December). Apparent per capita alcohol consumption: National, state, and regional trends, 1977-1995. (Surveillance Report \#43). Bethesda, MD: National Institutes for Alcohol Abuse and Alcoholism (NIAAA), Division of Biometry and Epidemiology.

Zador, P. K., Lund, A. K., Field, M., \& Weinberg, K. (1988). Alcohol-impaired driving laws and fatal crash involvement. Washington, DC: Insurance Institute for Highway Safety.

Zador, P. L. (1991). Alcohol-related relative risk of fatal driver injuries in relation to driver age and sex. Journal of Studies on Alcohol, 52(4), 302-310. 


\section{Alcohol Safety Laws and Fatal Crashes}

APPENDIX A: Estimates of Lives SAVEd By .08 BAC LeVEL

\begin{tabular}{|c|c|c|c|c|}
\hline STATE\# & $\begin{array}{l}\text { WOULD HAVE } \\
\text { BEEN SAVED } \\
\text { (conservative) }\end{array}$ & $\begin{array}{c}\text { WERE } \\
\text { SAVED } \\
\text { (conservallve) }\end{array}$ & $\begin{array}{c}\text { WOULD HAVE } \\
\text { BEEN SAVED } \\
\text { (liberal) }\end{array}$ & $\begin{array}{l}\text { WERE } \\
\text { SAVED } \\
\text { (llberal) }\end{array}$ \\
\hline 1 Alabama & & 28.0 & & 48.3 \\
\hline 2 Alaska & 2.2 & & 3.6 & \\
\hline 4 Arizona & 20.8 & & 33.7 & \\
\hline 5 Arkansas & 10.1 & & 16.6 & \\
\hline 6 Califomia & & 67.2 & & 118.1 \\
\hline 8 Colorado & 11.0 & & 18.0 & \\
\hline 9 Connecticut & 8.5 & & 14.0 & \\
\hline 10 Delaware & 3.3 & & 5.5 & \\
\hline 11 Dist of Columbia & 1,8 & & 3.0 & \\
\hline 12 Florida & & 49.7 & & 85.6 \\
\hline 13 Georgia & 29.2 & & 48.0 & \\
\hline 15 Hawaii & & 3.4 & & 5.8 \\
\hline 16 Idaho & 2.0 & 3.4 & 3.3 & 5.9 \\
\hline 17 Illinois & 16.6 & 16.6 & 26.2 & 29.2 \\
\hline 18 Indiana & 16.3 & & 26.1 & \\
\hline 19 lowa & 9.6 & & 15.9 & \\
\hline 20 Kansas & & 8.2 & & 14.2 \\
\hline 21 Kentucky & 15.5 & & 25.1 & \\
\hline 22 Louisiana & 21.4 & & 35.4 & \\
\hline 23 Maine & & 3.6 & & 6.2 \\
\hline 24 Maryland & 11.1 & & 18.5 & \\
\hline 25 Massachusetts & & 12.6 & & 22.4 \\
\hline 26 Michigan & 30.3 & & 50.0 & \\
\hline 27 Minnesota & 10.8 & & 17.6 & \\
\hline 28 Mississippi & 18.6 & & 30.0 & \\
\hline 29 Missouri & 28.4 & & 46.6 & \\
\hline 30 Montana & 6.7 & & 10.7 & \\
\hline $3 \uparrow$ Nebraska & 4.9 & & 8.1 & \\
\hline 32 Nevada & 8.9 & & 15.0 & \\
\hline 33 New Hampshire & & 3.8 & & 6.6 \\
\hline 34 New Jersey & 15.0 & & 25.2 & \\
\hline 35. New Mexico & & 9.8 & & 16.9 \\
\hline 36 New York & 23.4 & & 38.6 & \\
\hline 37 North Carolina & & 27.3 & & 47.0 \\
\hline 38 North Dakota & 2.1 & & 3.4 & \\
\hline 39 onlo & 26.7 & & 43.3 & \\
\hline 40 Oklahoma & 15.4 & & 24.9 & \\
\hline 41 Oregon & & 12.6 & & 21.7 \\
\hline 42 Pennsylvania & 36.5 & & 59.4 & \\
\hline 44 Rhode Island & 2.2 & & 3.7 & \\
\hline 45 South Carolina & 15.3 & & 24.6 & \\
\hline 46 South Dakota & 2.7 & & 4.4 & \\
\hline 47 Tennessee & 26.6 & & 43.0 & \\
\hline 48 Texas & 94.4 & & 155.1 & \\
\hline 49 Utah & & 3.7 & & 6.5 \\
\hline 50 Vermont & & 1.9 & & 3.3 \\
\hline 51 Virginia & & 22.7 & & 39.3 \\
\hline 53 Washington & 15.3 & & 25.0 & \\
\hline 54 West Virginia & 8.0 & & 12.7 & \\
\hline 55 Wisconsin & 17.5 & & 28.4 & \\
\hline 56 Wyoming & 2.1 & & 3.3 & \\
\hline Total & 590.3 & 274.5 & 965.0 & 476.9 \\
\hline
\end{tabular}


Alcohol Safety Laws and Fatal Crashes

\section{APPENDIX B: TREATMENT EFFECTS FOR ANALYSIS Without Time VARIABLE}

To illustrate the effect of including the two time trend variables in the analysis, a separate analysis was conducted in which the time trends were not entered. The resulting effect sizes are shown in Table B-1. These should be compared with Table 4 in the text.

TABLE B-1. EFFECT SIZES FOR ALCOHOL SAFETY AND SAFETY BELT LAWS FOR TWO GROUPS OF DRIVERS IN FATAL CRASHES

\begin{tabular}{c|l}
\hline Alcohol safety laws & $\begin{array}{l}\text { Drivers in fatal crashes } \\
\text { age } 21 \text { and older-Estimates }\end{array}$ \\
\hline Illegal per se laws (.10) & \\
.01 to .09 & $-16.54 \%$ \\
$.10+$ & $-11.60 \%$ \\
Per se 08 law & $-15.60 \%$ \\
.01 to .09 & $-12.15 \%$ \\
$10+$ & $-14.60 \%$ \\
Admin. license revocation law & -14 to .09 \\
$.10+$ &
\end{tabular}

* Significant at $p=.05$; all other significant at $p<.001$ 


\section{Alcohol Safety Laws and Fatal Crashes}

\section{APPENDIX C: TIME TREND}

A limitation in the WLS regression technique employed in the present study is that it is dependent upon the identification of the most significant variables that influence the proportion of drinking drivers in fatal crashes. While those variables listed above which were entered into the analysis include most of the factors identified in previous studies that influence fatal crashes, it is clear that there are other factors that are not included in the analysis that affect alcohol-related crashes. For example, there is no measure which tracks the media coverage of drinking driving issues which has been shown to be an important factor in the impact of new safety legislation and in traffic enforcement programs (Voas, Holder, \& Gruenewald, 1997). Nor is there a measure of the increasing use of sobriety checkpoints that have been shown to be effective in reducing alcohol-related crashes (Stuster \& Blowers, 1995; Lacey, Jones, \& Smith, 1999).

A common approach to dealing with the problem of excluded variables is to use a set of year dummy variables to reflect those unmeasured effects. There are two significant drawbacks to the use of year dummy variables. First, using a set of 15-year dummies is inefficient. It reduces the degrees of freedom providing a loss in statistical power. Secondly, each year is assessed separately and independently of their order or proximity to other years. Thus, rather than modeling any dynamic process or factor, this approach simply approximates a trend by overfitting it. Even if there is no trend, when year dummy variables are used, the analytic procedure may still attempt to fit residual fluctuation (essentially "modeling" error). One real danger of this over-fitting approach to modeling time effects is that it can deterministically wipe out time-related variances that are properly attributable to other causative dynamic variables (representing changing processes or conditions). It does this by slicing relevant, across-time "variance" into within-time periods.

Secondly, the "trend factor" (or more accurately, the extent to which causative factors changed systematically over time) captures some of the relevant variance accounted for by the gradual passage (shown in Table 1) of the various alcohol safety laws by an increasing proportion of states. This can reduce the amount of variance correctly attributable to the laws of interest. To minimize the first problem, a quadratic trend estimate was fitted to the 15-year dummy variable series to avoid the modeling of error, while maintaining an indicator of systematic change over time. Separate time trends for the drivers with BACs $\geq .10$ and drivers with BACs from .01 to .09 are shown in Figures C-1 and C-2. As can be seen the fit for the $>.10$ group is tighter than for the low BAC group, principally because the $\mathrm{N}$ of the $>.10$ group is larger. 


\section{Alcohol Safety Laws and Fatal Crashes}

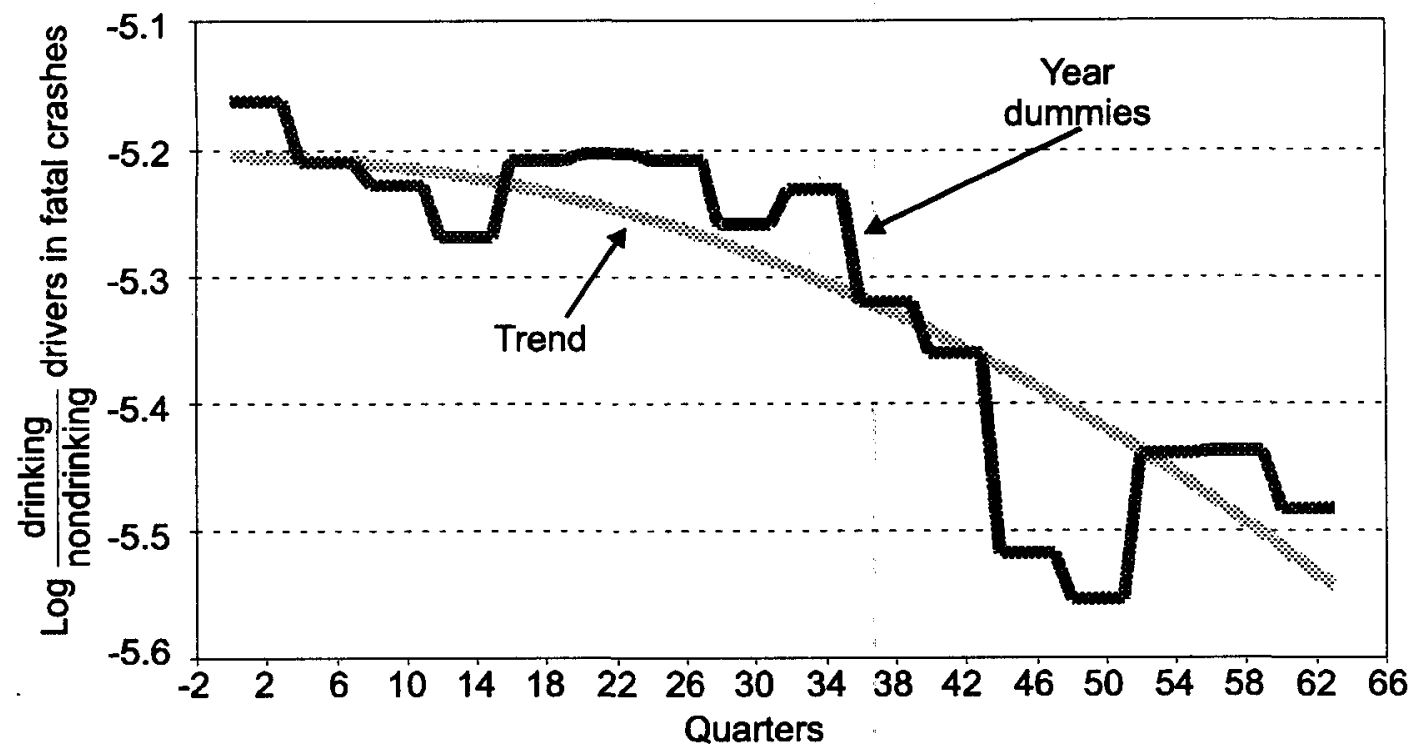

Trend: $\quad-.0000851765 \times$ (quarter $^{2}$ ) (where quarter $=0$ to 63 ) (from Jan-Mar 1982 through Oct-Dec 1997)

Year parameter estimates of the year effects for 50 states and dummies: the District of Columbia

FIGURE C-1. COMPARISON OF TREND ESTIMATES FOR IMPAIRED DRIVERS WITH .01 TO.09 BACS 
Alcohol Safety Laws and Fatal Crashes

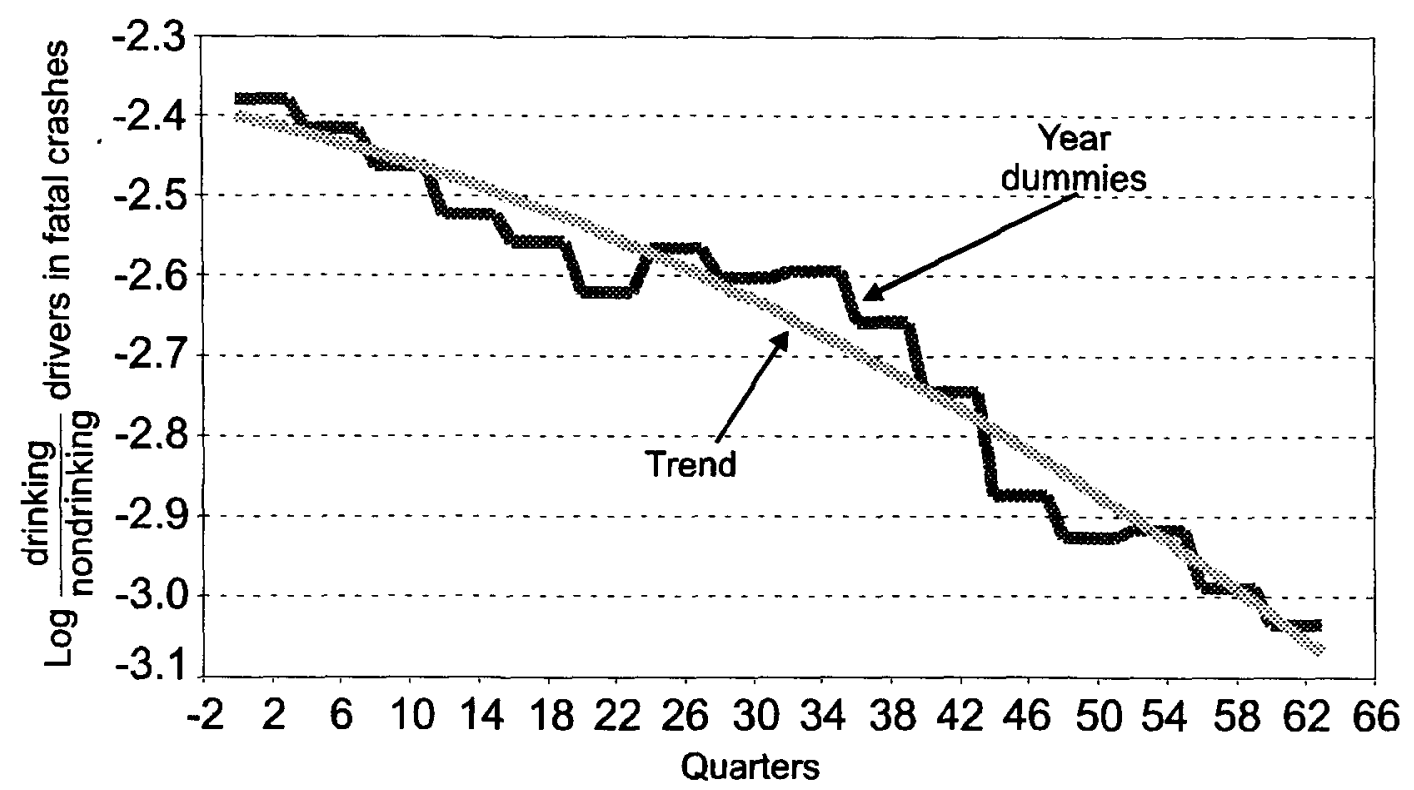

Trend: $\quad-.0050083072 \times$ (quarter) $-.0000889403 \times$ (quarter $^{2}$ ) (where quarter $=0$ to 63) (from Jan-Mar 1982 through Oct-Dec 1997) Year parameter estimates of the year effects for 50 states and dummies: the District of Columbia

FIGURE C-2. COMPARISON OF TREND ESTIMATE FOR INTOXICATED (.10†) RATES 


\section{Alcohol Safety Laws and Fatal Crashes}

Table C-1 shows the correlation of the quadratic trend estimate with each of the three safety law variables. All three laws are significantly related to both trends, suggesting that some of the variance correctly attributable to the three safety laws is captured by the time trends.

TABLE C-1. CORRELATIONS OF ALCOHOL SAFETY LAWS WITH ESTIMATES FOR TIME TREND

\begin{tabular}{l|lll|l}
\hline \multirow{2}{*}{$\begin{array}{l}\text { Coefficients for } \\
\text { Time Trend Fit }\end{array}$} & \multicolumn{2}{|l|}{$\begin{array}{l}\text { Correlations (using law dummies, } \\
\text { disaggregated by state within quarter) }\end{array}$} & \\
\cline { 2 - 4 } & $.08 @$ & $.10 @$ & ALR@ & $N$ \\
\hline for .01-.09 data & -.299 & -.327 & -.366 & $N$ \\
for .10+ data & -.293 & -.358 & -.382 & \\
\hline
\end{tabular}

\section{References}

Lacey, J., Jones, R., \& Smith, R. (1999). An evaluation of checkpoint Tennessee: Tennessee's statewide sobriety checkpoint program (DOT HS 808 841). Washington, DC: U.S. Department of Transportation.

Stuster, J. W., \& Blowers, M. A. (1995). Experimental evaluation of sobriety checkpoint programs (DTNH22-91-C-07204). Washington, DC: National Highway Safety Administration, 400 Seventh Street, SW, Washington, DC 20905.

Voas, R. B., Holder, H. D., \& Gruenewald, P. J. (1997). The effect of drinking and driving interventions on alcohol-involved traffic crashes within a comprehensive community trial. Addiction, 92 (Supplement 2), S221-S236. 
DOT HS 808980

September 1999 